\title{
IMPACT OF COIL FACTORS ON A HYDRAULIC ELECTRIC INERTER BASED VEHICLE SUSPENSION
}

\author{
HONGDANG ZHANG \\ School of Automotive and Traffic Engineering, Jiangsu University, Zhenjiang, China, and \\ Changzhou Vocational Institute of Mechatronic Technology, Changzhou, China \\ e-mail: zhanghongdangcz@163.com \\ YUJIE SHEN \\ School of Automotive and Traffic Engineering, Jiangsu University, Zhenjiang, China, and \\ State Key Laboratory of Automotive Safety and Energy, Beijing, China \\ e-mail: shenliang6018@163.com \\ HONGTU YANG \\ School of Automotive and Traffic Engineering, Jiangsu University, Zhenjiang, China, and \\ Changzhou Vocational Institute of Mechatronic Technology, Changzhou, China \\ e-mail: czjdhongtuyang9668@163.com
}

\begin{abstract}
This paper concerns the impact of coil factors on a hydraulic electric inerter-based vehicle suspension. A hydraulic electric inerter device is first introduced, and the dynamic model of a quarter car is established. Subsequently, the influences of the coil factors on the body acceleration, suspension working space and dynamic tire load are investigated in both the time and frequency domain. Results show that the coil factors have a slight effect on the vehicle suspension performance, decreasing the root-mean-square (RMS) of the vehicle body acceleration and increasing the RMS of the suspension working space and dynamic tire load.

Keywords: vehicle, suspension, hydraulic electric, inerter
\end{abstract}

\section{Introduction}

With the goal of improving vehicle suspension performance, active suspensions (Ding et al., 2019; Chen et al., 2017; Xue et al., 2019) and semi-active suspensions (Huang et al., 2013; Rashid et al., 2011; Chen et al., 2015) have been proposed due to their excellent vibration isolation performance. More recently, a new two-terminal mechanical element, the inerter (Smith, 2002), was invented and applied to various engineering fields, such as vehicle suspensions (Smith and Wang, 2004; Wang et al., 2017; Shen et al., 2019a), civil engineering (Wang et al., 2010; Lazar et al., 2014) and aerospace engineering (Li et al., 2016, 2017). The research has shown that, in comparison to the traditional spring-damper network, the vibration isolation performance of a mechanical system can be dramatically improved by employing an inerter element.

Generally, an inerter can be mechanically realized by various structures, such as the rack-andpinion (Papageorgiou and Smith, 2005), ball-screw (Papageorgiou et al., 2009; Sun et al., 2016) and fluid-based forms (Swift et al., 2013; Shen et al., 2016a; Liu et al., 2018). Moreover, on the basis of the mechanical inerter device, a motor can be attached to obtain a new type of the inerter structure, such as the mechatronic inerter (Wang and Chan, 2011) and the hydraulic electric inerter (Yang et al., 2015; Shen et al., 2019b). The mechatronic or hydraulic electric inerter have the metrics that it can use the electric elements to simulate impedanceof the corresponding mechanical elements, which can solve high complexities of the mechanical network. For motor 
analysis, one can use in a vibration isolation system not only vibration control (Amati et al., 2011), but also can act as an energy-harvesting device (Liu et al., 2017). However, the effects of coil factors, such as the coil resistor and inductor, have drawn much attention (Shi et al., 2014). As a consequence, this paper will concentrate on the study of the impact of the coil resistor and inductor on the hydraulic electric inerter-based vehicle suspension. The paper is arranged as follows.

In Section 2, the hydraulic electric inerter (HEI) device is presented. On the basis of the hydraulic electric inerter element, the dynamic model of a quarter car model is established in Section 3. By considering the coil resistor and inductor factors, their impacts on vehicle suspension performance are discussed in detail in Section 4. Some conclusions are obtained in Section 5 .

\section{Hydraulic electric inerter}

The mechatronic inerter (Wang and Chan, 2011) has the feature that it is always in parallel with the electric network, such that the electric elements can be used to simulate the target mechanical impedance. It is worth noting that a single linear motor was also adopted as an electromagnetic inerter-based vibration suppression device (Gonzalez-Buelga et al., 2015). In this study, a novel hydraulic electric inerter, which consists of a hydraulic piston inerter and a linear motor is introduced. The schematic of the hydraulic electric inerter, called an HEI device, is presented in Fig. 1.

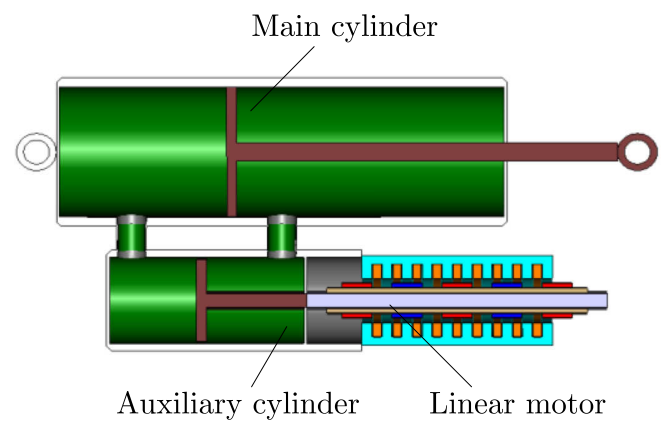

Fig. 1. Schematic of an HEI device

It is shown that the piston rod and the main cylinder are the two terminals of the HEI device. The HEI device involves the main cylinder, the auxiliary cylinder and the linear motor. When there is a fluid flowing between the main and auxiliary cylinder, different section areas of the two cylinders will lead to motion transmission between the piston in the main cylinder and the piston in the auxiliary cylinder. Note that the piston rod of the auxiliary cylinder is connected to the mover of the linear motor, and voltage can be generated when a pair of forces is applied to the HEI device. The impedance of the HEI device can be expressed as (Yang et al., 2015)

$$
\frac{F(s)}{v(s)}=\left(\frac{S_{1}}{S_{2}}\right)^{2} m s+\frac{K_{m}}{R_{e}+L_{e} s+Z_{e}(s)}
$$

where $S_{1}$ and $S_{2}$ are sectional areas of the main and auxiliary cylinder, $m$ is mass of the piston rod and the moving rod of the linear motor, $F(s)$ and $v(s)$ are the Laplace forms of the force and velocity of the two terminals of the HEI device, $K_{m}$ is the motor coefficient, for the HEI device, $K_{m}=\left(S_{1} / S_{2}\right)^{2} k_{e} k_{t}, k_{e}$ is the voltage coefficient, $k_{t}$ is the force coefficient, $R_{e}$ is the coil resistor, $L_{e}$ is the coil inductor. $Z_{e}(s)$ is the impedance of the external electric circuit. It is seen that the first section of equation (2.1) is the mechanical inertance, and can be expressed as

$$
b_{m}=m\left(\frac{S_{1}}{S_{2}}\right)^{2}
$$




\section{Quarter car model}

Based on the proposed HEI device, a quarter car model is considered in this Section. The mechanical network has a basic series layout (Shen et al., 2017), in which the HEI is in series with a mechanical damper. The external electric network comes from a five-element (Jiang and Smith, 2011). The quarter car model is depicted in Fig. 2, where $m_{s}$ is the sprung mass, $m_{u}$ is the unsprung mass, $K$ is the supporting spring of the suspension, $K_{t}$ is tire stiffness, $z_{s}, z_{u}$ and $z_{r}$ are vertical displacements of the sprung mass, unsprung mass and the random road input, $c_{m}$ is mechanical damping, $z_{b}$ is vertical displacement of the HEI device, $L$ is the inductor, $R_{1}, R_{2}$ and $R_{3}$ are resistors, $C$ is capacitor, and $V_{g}$ is voltage of the external circuit.

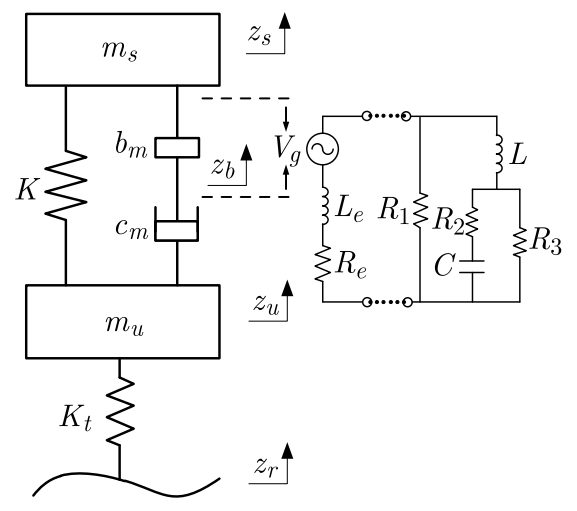

Fig. 2. Quarter car model

The dynamic equations of the quarter car model are expressed as

$$
\begin{aligned}
& m_{s} \ddot{z}_{s}+K\left(z_{s}-z_{u}\right)+b_{m}\left(\ddot{z}_{s}-\ddot{z}_{b}\right)+F_{t}=0 \\
& m_{u} \ddot{z}_{u}+K_{t}\left(z_{u}-z_{r}\right)-K\left(z_{s}-z_{u}\right)-b_{m}\left(\ddot{z}_{s}-\ddot{z}_{b}\right)-F_{t}=0 \\
& b_{m}\left(\ddot{z}_{s}-\ddot{z}_{b}\right)+F_{t}=c_{m}\left(\dot{z}_{b}-\dot{z}_{u}\right)
\end{aligned}
$$

where $F_{t}$ is the damping force generated by the linear motor. The Laplace form of $F_{t}$ is

$$
F_{t}(s)=\left(\frac{S_{1}}{S_{2}}\right)^{2}\left(\frac{k_{t} k_{e}}{R_{e}+s L_{e}+Z_{e}(s)}\right)\left[\dot{z}_{s}(s)-\dot{z}_{b}(s)\right]
$$

The impedance of the external circuit is

$$
Z_{e}(s)=\frac{1}{R_{1}}+\frac{1}{L s+\frac{1}{\frac{1}{R_{3}}+\frac{1}{\frac{1}{C s}+R_{2}}}}
$$

The parameters of the quarter car model are shown in Table 1.

The suspension parameters are optimized by the approach presented in (Shen et al., 2016b), and the detailed values are shown in Table 2. It is noting that in the optimal design of the vehicle HE-ISD suspension, all of the three vehicle suspension performance indexes, namely, the RMS of vehicle body acceleration, the RMS of the suspension working space and the RMS of the dynamic tire load are taken into account. It is a multi-objective optimization problem, and a representative result is selected to show the advantages of the vehicle HE-ISD suspension.

Compared to a traditional passive suspension considered in (Shen et al., 2016b), the performance indexes are shown in Table 3 and the responses of the vehicle Inerter-Spring-Damper (ISD) suspension based on the HEI device, here, called vehicle HE-ISD suspension, are presented in Figs. 3 to 6. 
Table 1. Model parameters

\begin{tabular}{|l|c|}
\hline \multicolumn{1}{|c|}{ Parameters } & Values \\
\hline \hline Vehicle body mass $m_{s}[\mathrm{~kg}]$ & 320 \\
\hline Unsprung mass $m_{u}[\mathrm{~kg}]$ & 45 \\
\hline Suspension spring stiffness $K[\mathrm{~N} / \mathrm{m}]$ & 22000 \\
\hline Tire spring stiffness $K_{t}[\mathrm{~N} / \mathrm{m}]$ & 190000 \\
\hline Coil resistor of linear motor $R_{e}[\Omega]$ & 3.8 \\
\hline Coil inductor of linear motor $L_{e}[\mathrm{mH}]$ & 26 \\
\hline Force coefficient $k_{e}[\mathrm{NA}]$ & 100 \\
\hline Voltage coefficient $k_{t}[\mathrm{Vm} / \mathrm{s}]$ & 81 \\
\hline
\end{tabular}

Table 2. Optimized parameters

\begin{tabular}{|l|c|}
\hline \multicolumn{1}{|c|}{ Parameters } & Values \\
\hline \hline Mechanic inertance $b_{m}[\mathrm{~kg}]$ & 93.57 \\
\hline Mechanical damper $c_{m}[\mathrm{Ns} / \mathrm{m}]$ & 1840 \\
\hline Resistor $R_{1}[\Omega]$ & 124361.5 \\
\hline Resistor $R_{2}[\Omega]$ & 11.9998 \\
\hline Resistor $R_{3}[\Omega]$ & 98134.3 \\
\hline Inductor $L[\mathrm{H}]$ & 0.2111 \\
\hline Capacitor $C[\mathrm{~F}]$ & 0.0037 \\
\hline
\end{tabular}

Table 3. Performance indexes of vehicle suspension

\begin{tabular}{|l|c|c|c|}
\hline \multicolumn{1}{|c|}{ RMS values } & Passive suspension & HE-ISD suspension & Improvement \\
\hline \hline Vehicle body acceleration $\left[\mathrm{m} / \mathrm{s}^{2}\right]$ & 2.2087 & 2.1942 & $0.66 \%$ \\
\hline Suspension working space $[\mathrm{m}]$ & 0.0223 & 0.0177 & $20.63 \%$ \\
\hline Dynamic tire load $[\mathrm{N}]$ & 1505.2 & 1336.6 & $11.20 \%$ \\
\hline
\end{tabular}

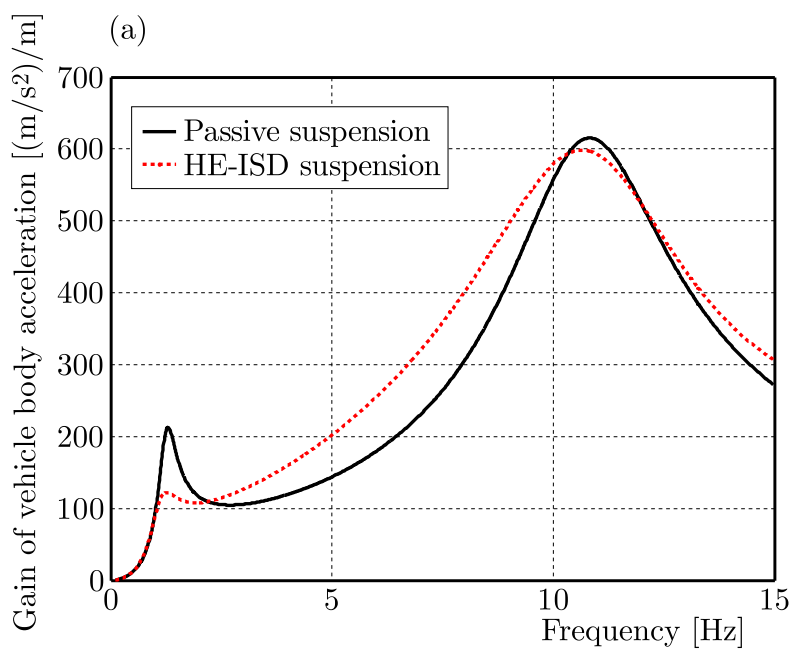

(b)

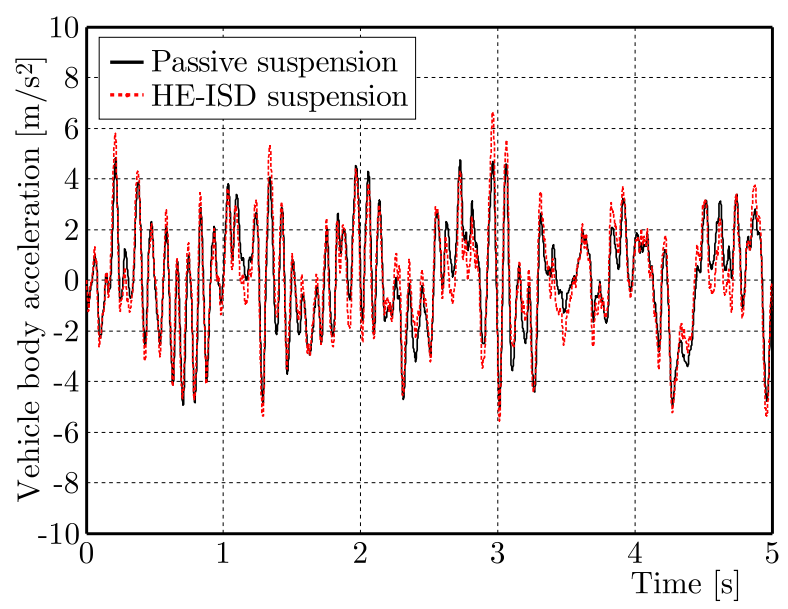

Fig. 3. Responses of vehicle body acceleration 
(a)

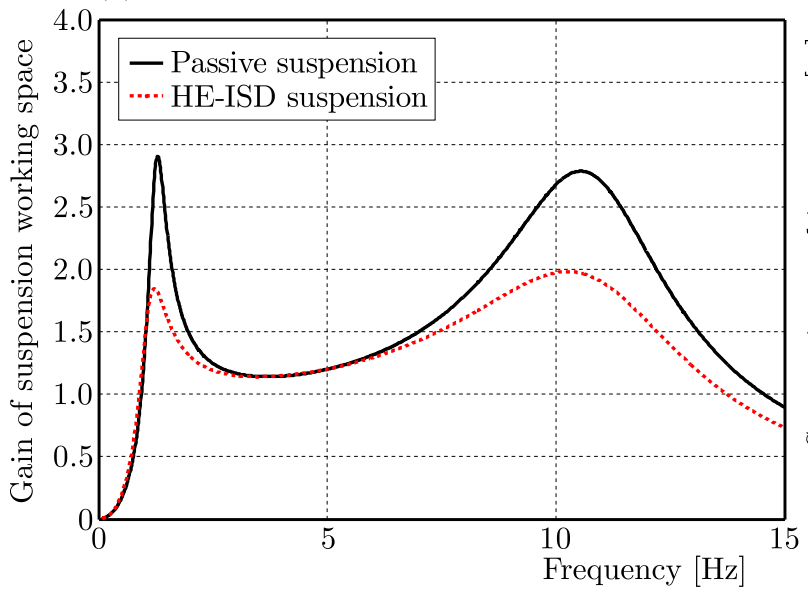

(b)

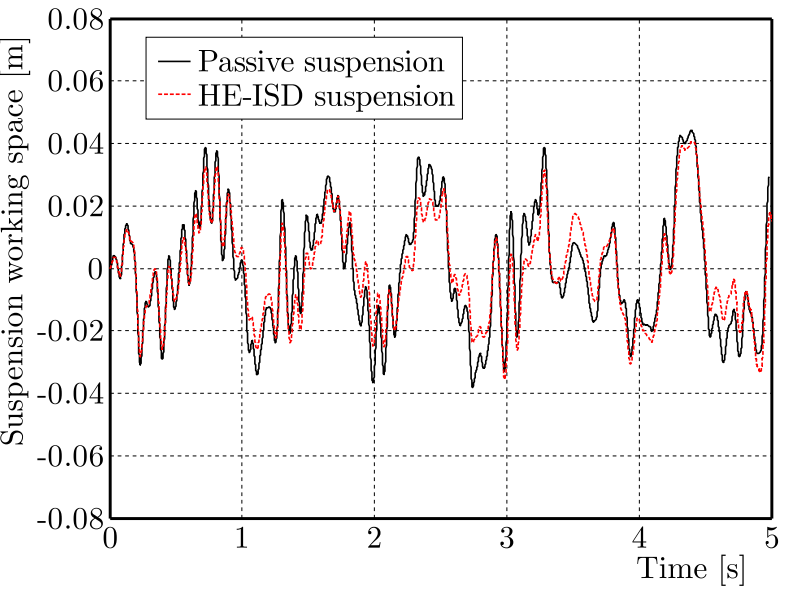

Fig. 4. Responses of suspension working space

(a)

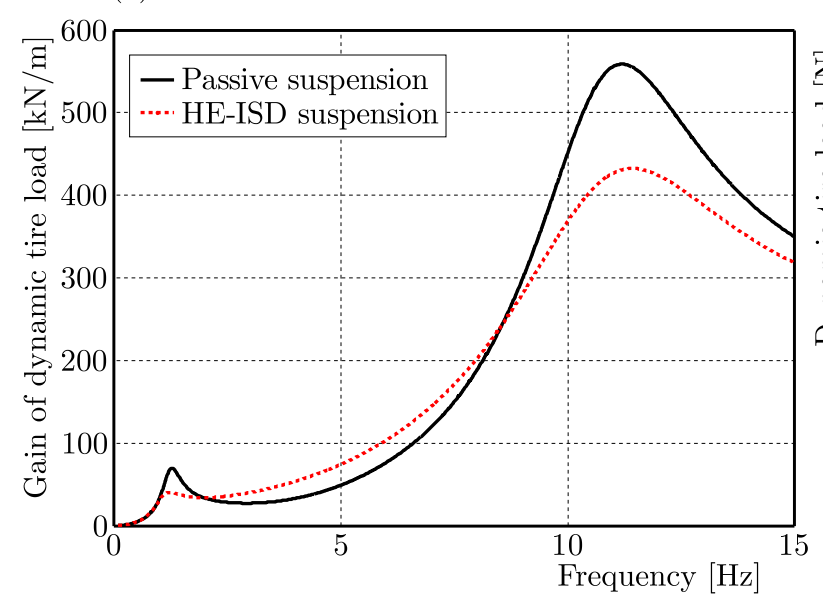

(b)

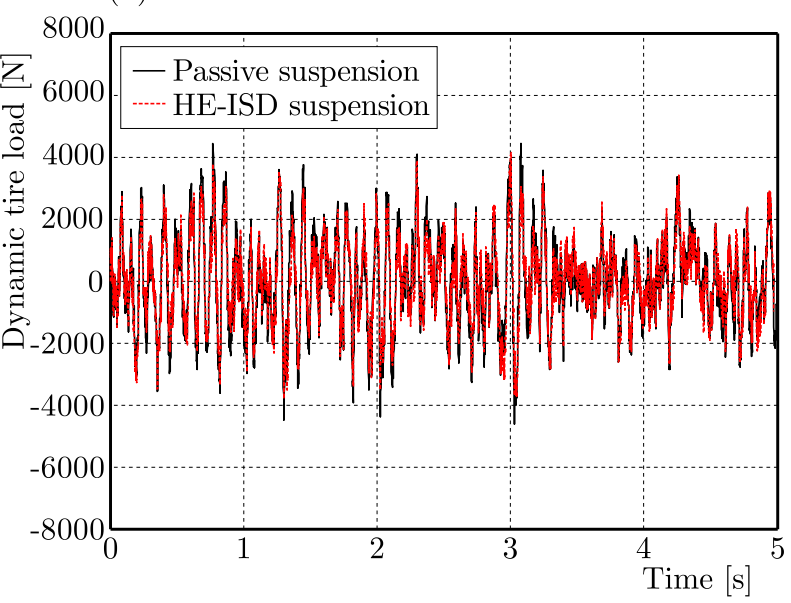

Fig. 5. Responses of dynamic tire load

It can be seen that, compared to the passive suspension system, the vibration isolation performance of the vehicle HE-ISD suspension is dramatically improved. In the frequency analysis, the two peaks of the gain of vehicle body acceleration are lower than those of the passive suspension. However, the gain in the middle frequency is higher than that of the passive one. The gains of the suspension working space of the vehicle HE-ISD suspension are all lower than those of the passive suspension over all considered frequencies. With the same trends of vehicle body acceleration, the two peaks of the gains of the dynamic tire load are lower than those of the passive one, but in the middle frequency, the gain is slightly higher than that of the passive suspension. In terms of the performance indexes in the time domain, namely, the root-mean-square (RMS) of the vehicle body acceleration, suspension working space and dynamic tire load, the improvements are $0.66 \%, 20.63 \%$ and $11.20 \%$, respectively. It is noted that the HE-ISD suspension is superior to the passive suspension for the suspension working space and dynamic tire load, but for the body acceleration, the improvement is relatively small.

\section{Impact of coil factors on vehicle suspension performance}

In this Section, the impact of the coil factors on the vehicle suspension performance will be analyzed in detail, and three scenarios will be discussed, considering the coil resistor, considering the coil inductor and considering both of the coil resistor and inductor. 


\subsection{Effect of the coil resistor}

Considering the coil resistor, Table 4 shows comparisons of performance indexes, and Figs. 6 through 8 show differences between the vehicle HE-ISD suspension and the suspension when considering the resistor only.

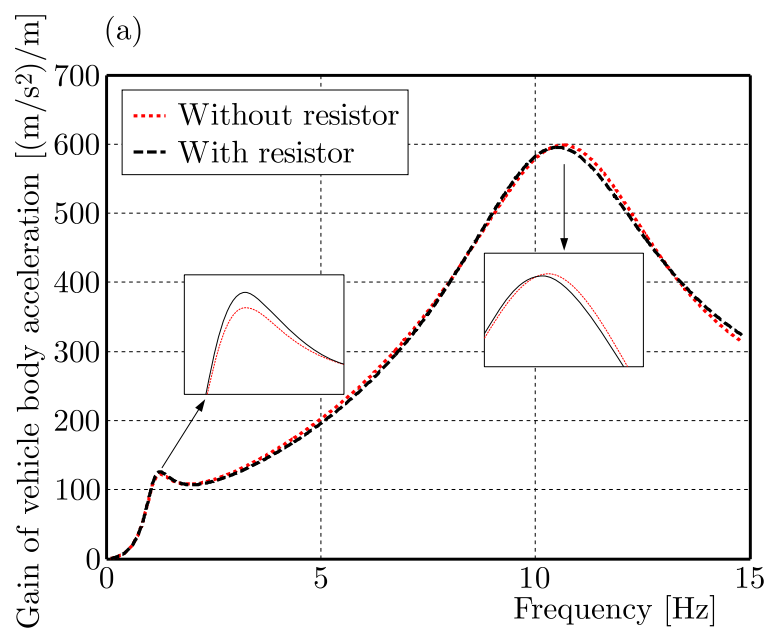

(b)

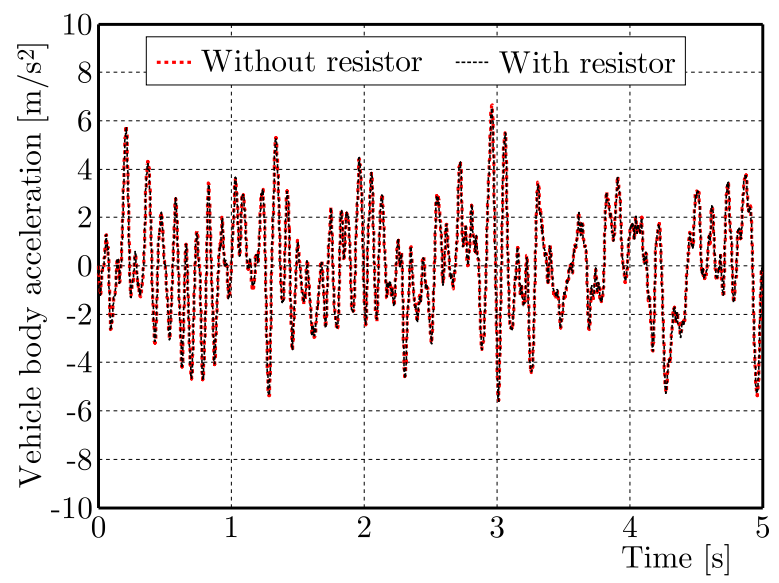

Fig. 6. Comparisons of vehicle body acceleration with resistor

(a)

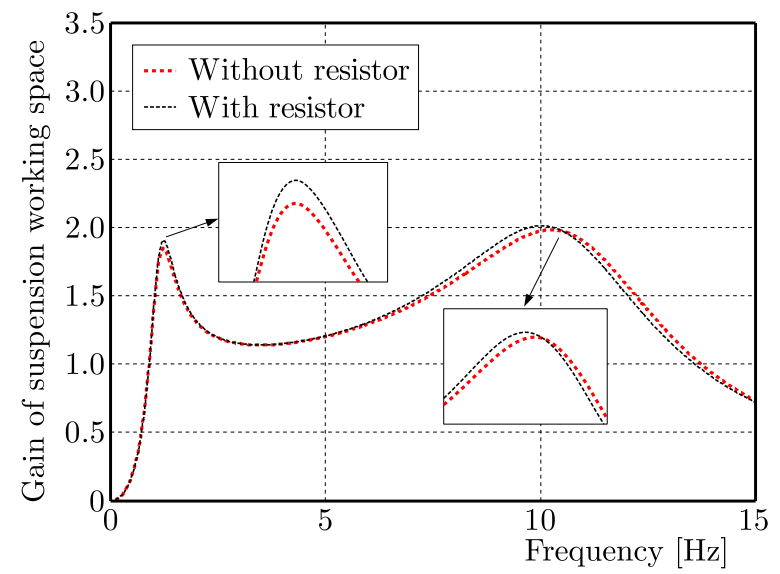

(b)

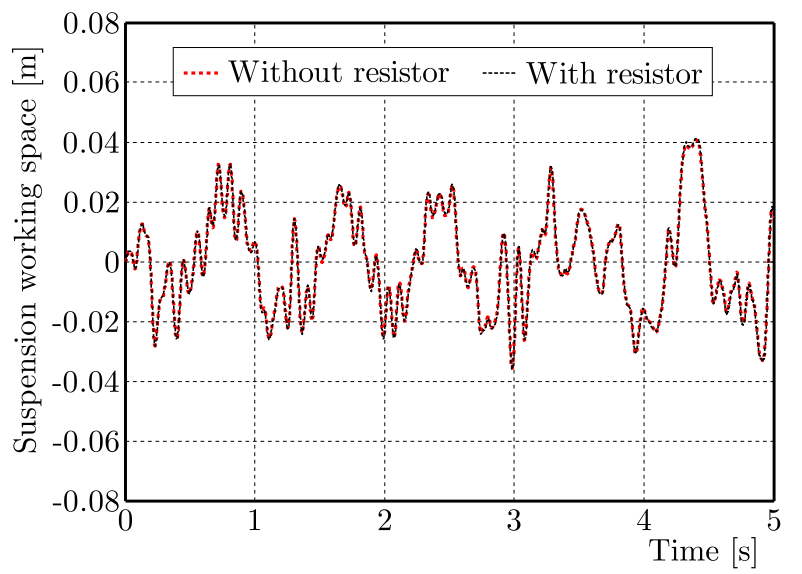

Fig. 7. Comparisons of suspension working space with resistor

(a)

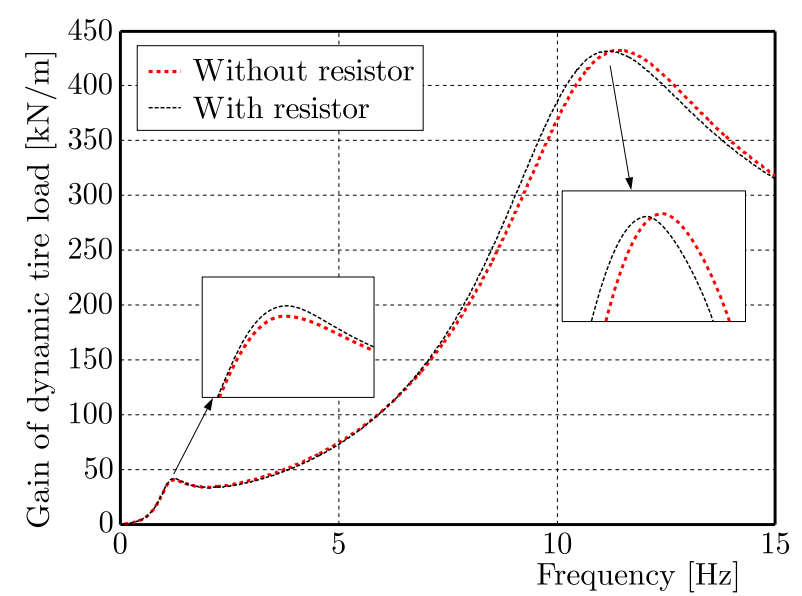

(b)

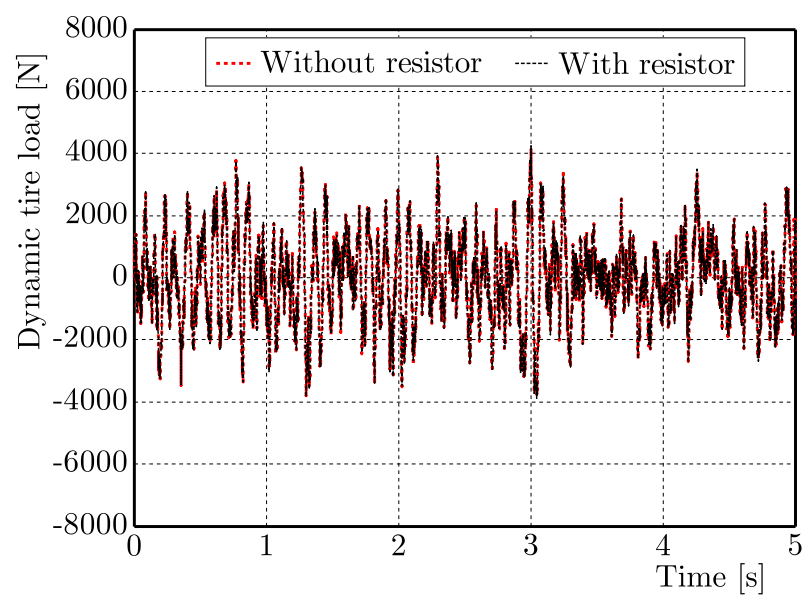

Fig. 8. Comparisons of dynamic tire load with resistor 
Table 4. Comparisons of performance indexes of the vehicle suspension with resistor

\begin{tabular}{|l|c|c|c|}
\hline \multicolumn{1}{|c|}{ RMS values } & Without resistor & With resistor & Improvement \\
\hline \hline Vehicle body acceleration $\left[\mathrm{m} / \mathrm{s}^{2}\right]$ & 2.1942 & 2.1842 & $1.11 \%$ \\
\hline Suspension working space $[\mathrm{m}]$ & 0.0177 & 0.0181 & $18.83 \%$ \\
\hline Dynamic tire load $[\mathrm{N}]$ & 1336.6 & 1345.1 & $10.64 \%$ \\
\hline
\end{tabular}

It is noted that for the gain of vehicle body acceleration, when considering the coil resistor, the resonance peak in the low frequency will increase. In contrast, the resonance peak in the high frequency will slightly decrease, and the resonance frequency will also decrease. The same trends are also found in terms of the gain of the dynamic tire load. For the suspension working space, both the resonance peaks in the low frequency and high frequency will increase when considering the coil resistor factors. For the performance indexes, the RMS of the vehicle body acceleration will decrease, and the RMS of the suspension working space and dynamic tire load will increase. However, in comparison to the passive suspension, the improvements are still 1.11\%, $18.83 \%$ and $10.64 \%$, respectively.

\subsection{Effect of the coil inductor}

Considering the coil inductor, Table 5 shows comparisons of performance indexes, and Figs. 9 through 11 show the differences between the HE-ISD suspension and the suspension when considering the inductor only.

Table 5. Comparisons of performance indexes of the vehicle suspension with inductor

\begin{tabular}{|l|c|c|c|}
\hline \multicolumn{1}{|c|}{ RMS values } & Without inductor & With inductor & Improvement \\
\hline \hline Vehicle body acceleration $\left[\mathrm{m} / \mathrm{s}^{2}\right]$ & 2.1942 & 2.1842 & $1.11 \%$ \\
\hline Suspension working space $[\mathrm{m}]$ & 0.0177 & 0.0179 & $19.73 \%$ \\
\hline Dynamic tire load $[\mathrm{N}]$ & 1336.6 & 1345.2 & $10.63 \%$ \\
\hline
\end{tabular}

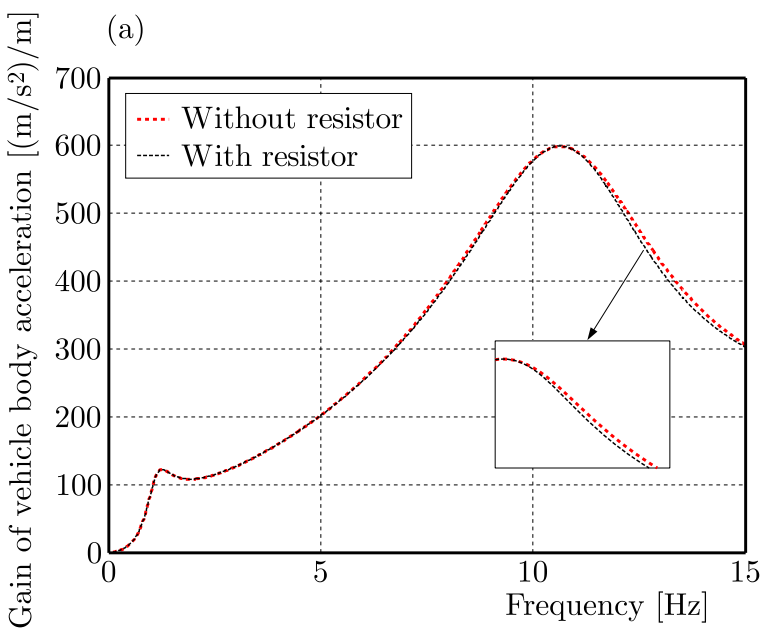

(b)

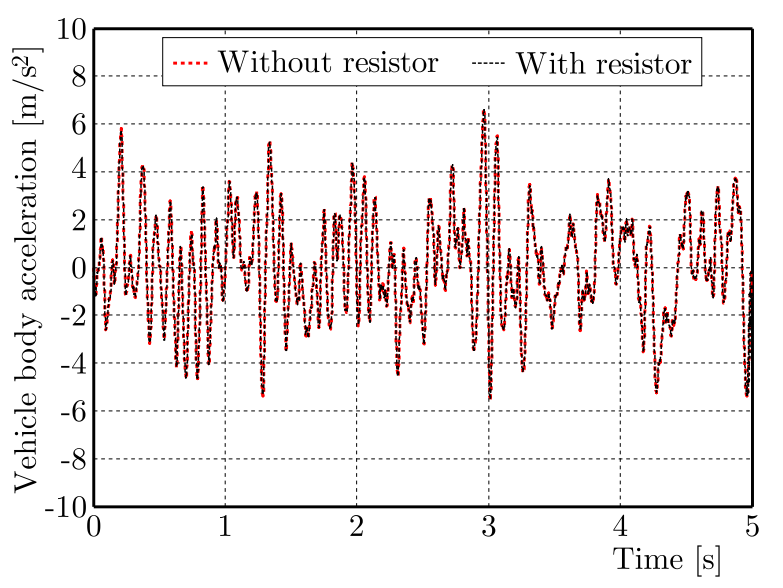

Fig. 9. Comparisons of the vehicle body acceleration with inductor

It is seen that when considering the coil inductor, there are no obvious changes in the low frequency. However, for the resonance peaks in the high frequency, the gain of the vehicle body acceleration is slightly decreased, while the gains of the suspension working space and dynamic tire load are dramatically increased. For the performance indexes, the RMS of the vehicle body acceleration will decrease, and the RMS of the suspension working space and dynamic tire load 
(a)

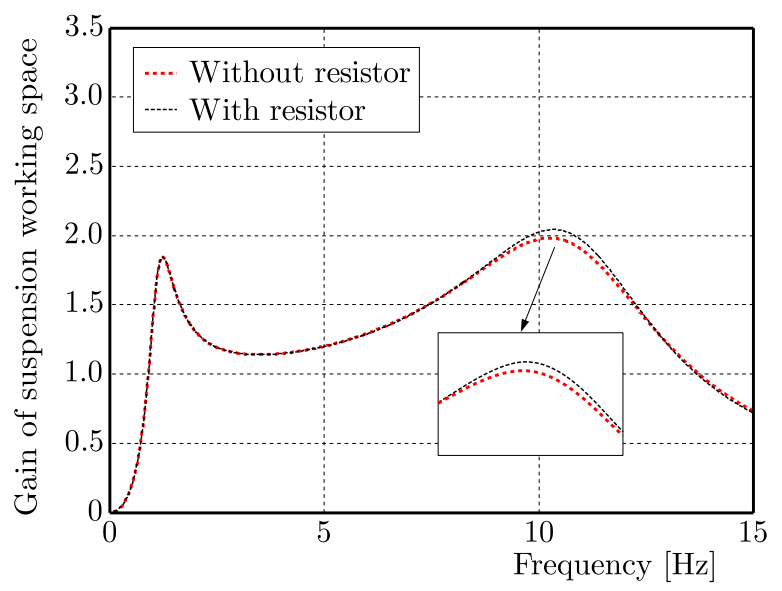

(b)

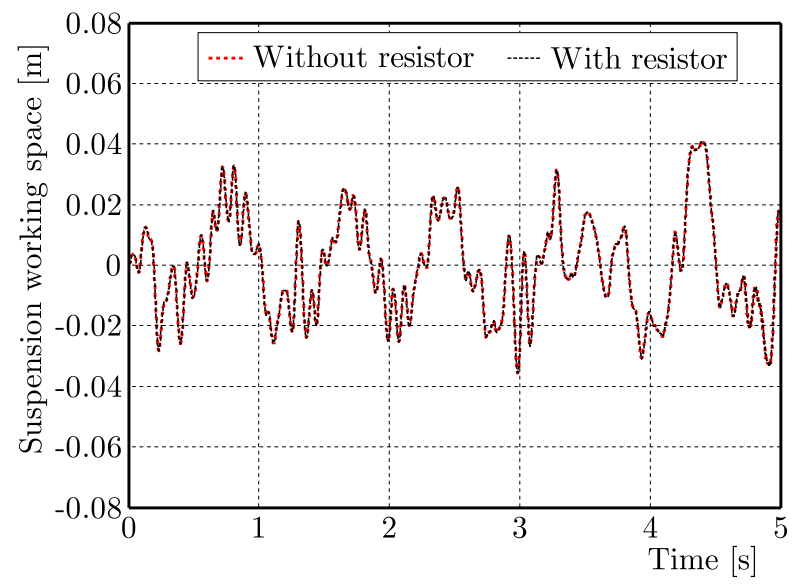

Fig. 10. Comparisons of suspension working space with inductor

(a)

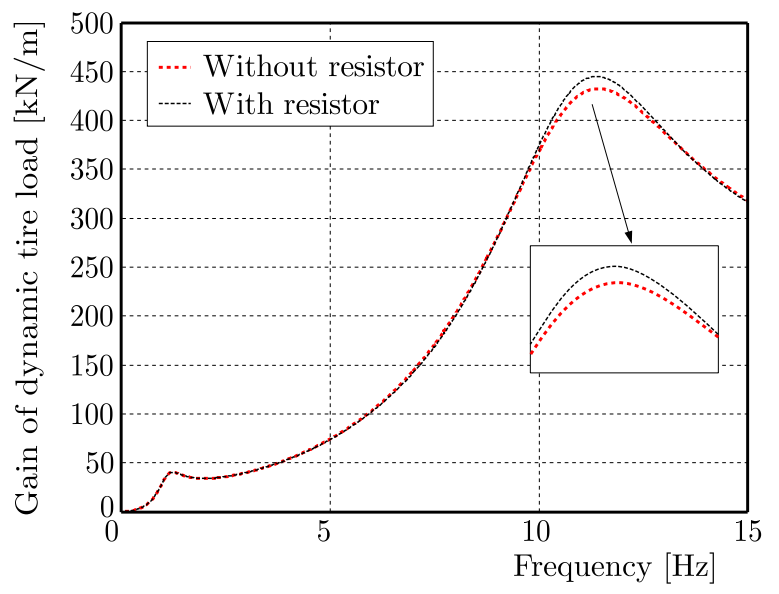

(b)

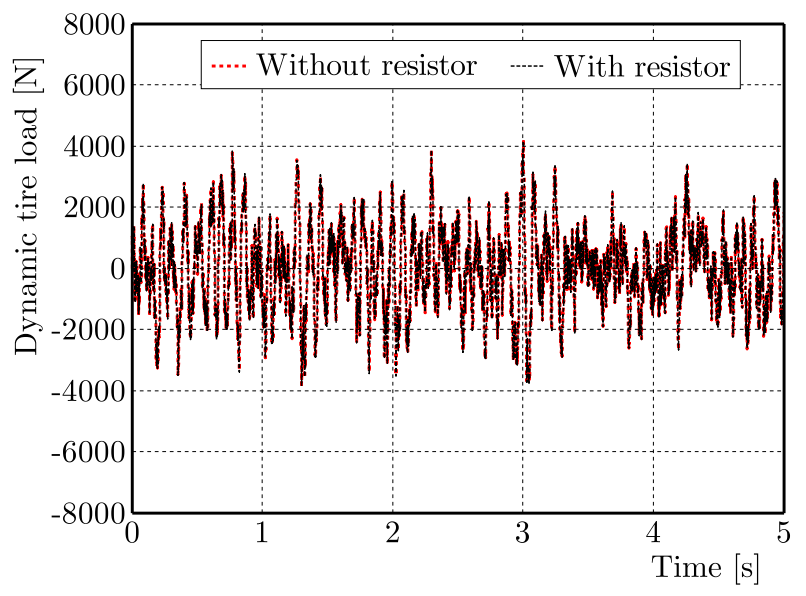

Fig. 11. Comparisons of dynamic tire load with inductor

will increase. However, in comparison to the passive suspension, the improvements are $1.11 \%$, $19.73 \%$ and $10.63 \%$.

\subsection{Effect of both the coil resistor and inductor}

Considering both the coil resistor and inductor, Table 6 shows comparisons of performance indexes, and Figs. 12 through 14 show differences between the HE-ISD suspension and the suspension when considering both factors.

Table 6. Comparisons of performance indexes of the vehicle suspension with resistor and inductor

\begin{tabular}{|l|c|c|c|}
\hline \multicolumn{1}{|c|}{ RMS values } & $\begin{array}{c}\text { Without resistor } \\
\text { and inductor }\end{array}$ & $\begin{array}{c}\text { With resistor } \\
\text { and inductor }\end{array}$ & Improvement \\
\hline \hline Vehicle body acceleration $\left[\mathrm{m} / \mathrm{s}^{2}\right]$ & 2.1942 & 2.1763 & $1.47 \%$ \\
\hline Suspension working space $[\mathrm{m}]$ & 0.0177 & 0.0181 & $18.83 \%$ \\
\hline Dynamic tire load $[\mathrm{N}]$ & 1336.6 & 1345.1 & $10.21 \%$ \\
\hline
\end{tabular}

It is noted that for the gain of vehicle body acceleration, when considering the coil resistor and inductor, the resonance peak in the low frequency will increase. In contrast, the resonance 


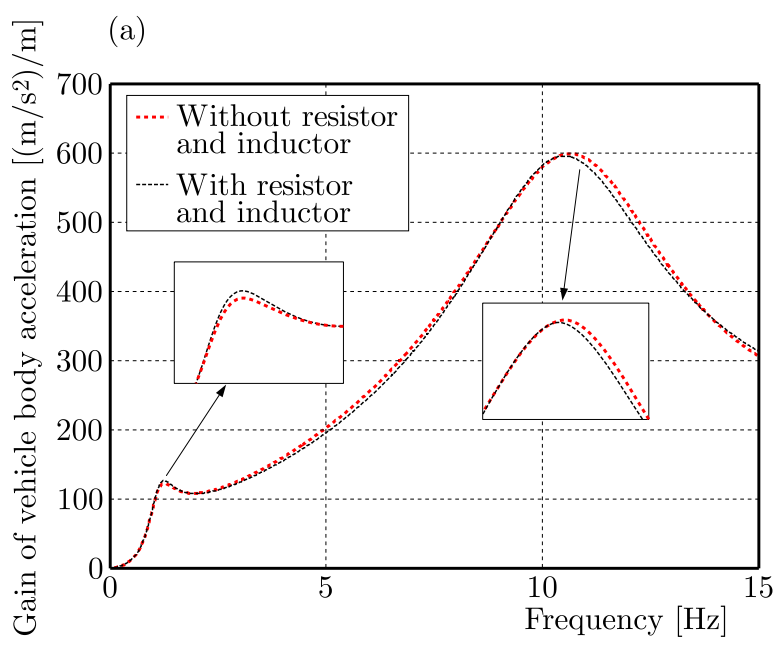

(b)

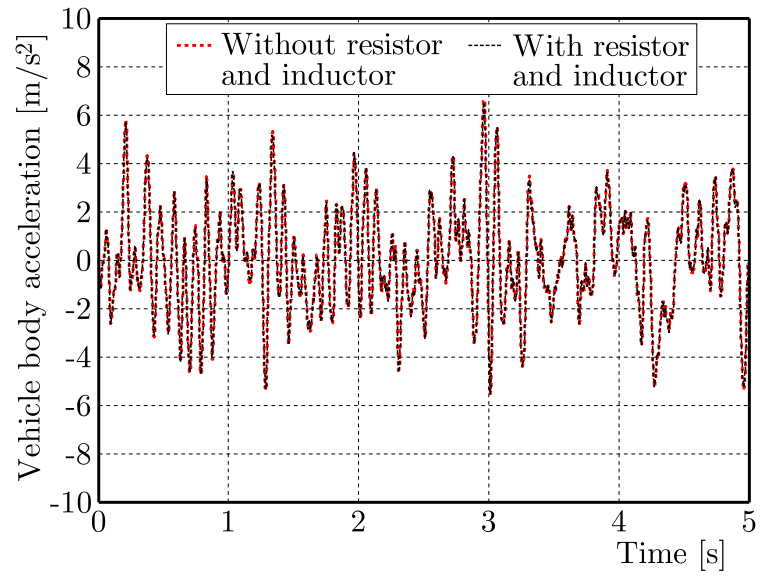

Fig. 12. Comparisons of vehicle body acceleration with resistor and inductor

(a)

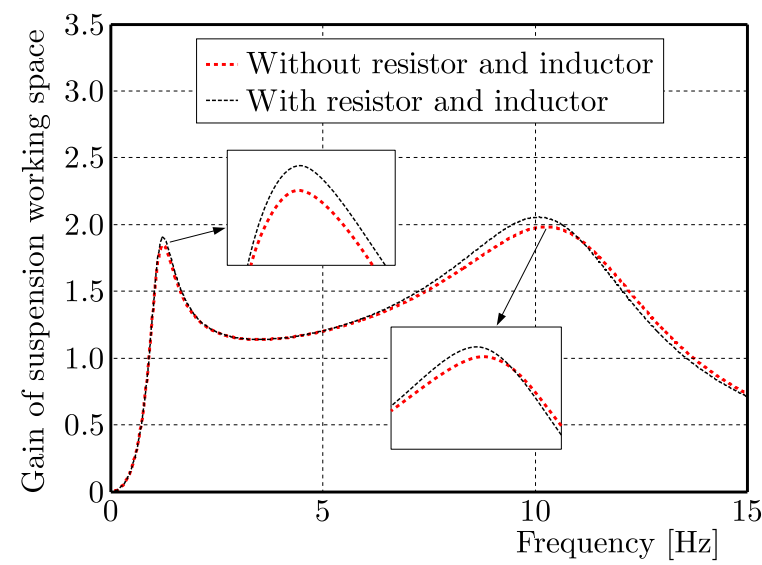

(b)

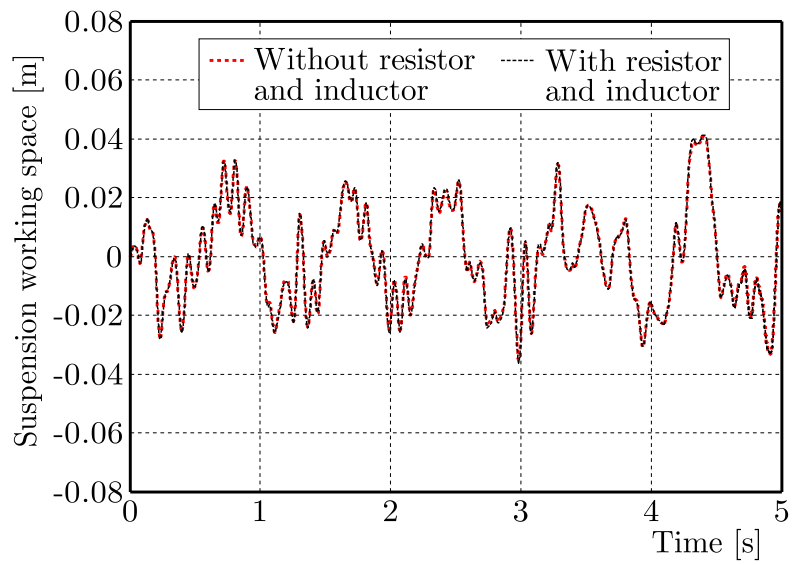

Fig. 13. Comparisons of suspension working space with resistor and inductor

(a)

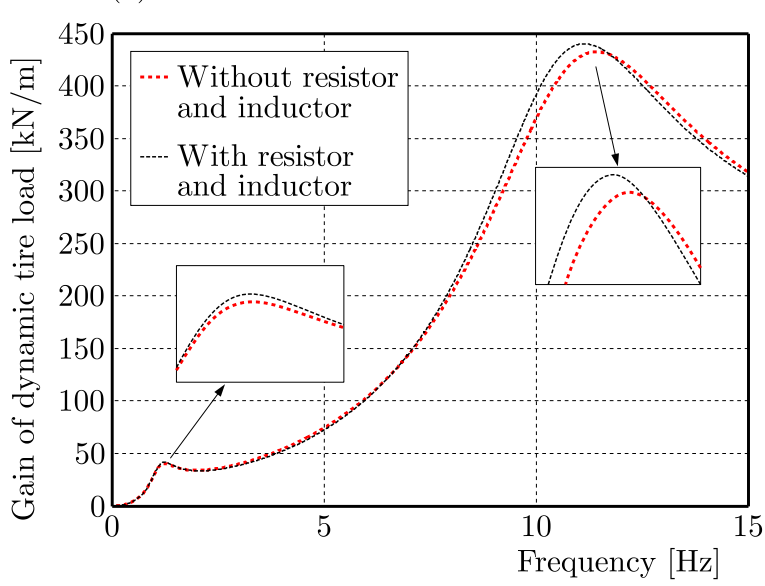

(b)

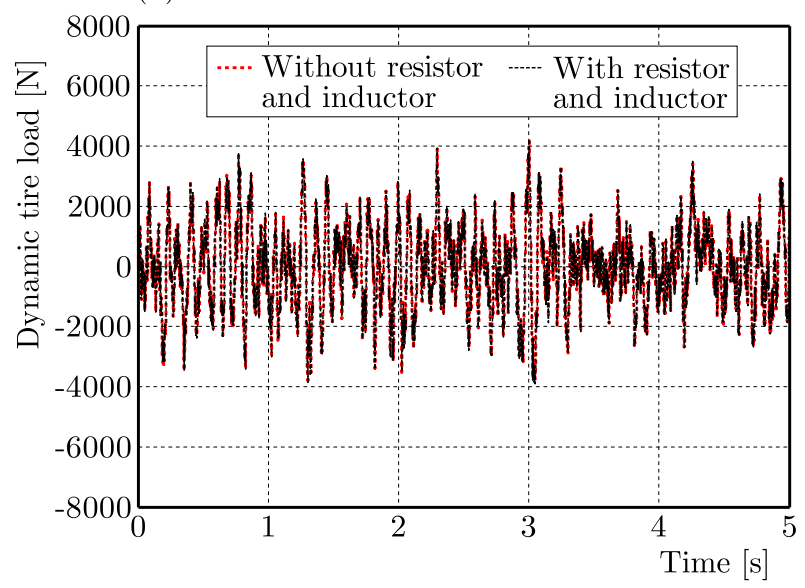

Fig. 14. Comparisons of dynamic tire load with resistor and inductor

peak in the high frequency will slightly decrease, and the resonance frequency will also decrease. The same trends are also found in terms of the gain of the dynamic tire load. For the suspension working space, both the resonance peaks in the low frequency and high frequency will increase 
when considering the coil resistor and inductor, and the resonance frequency in the high frequency will decrease. For the performance indexes, the RMS of the vehicle body acceleration will decrease, and both the RMS values of the suspension working space and dynamic tire load will increase. However, in comparison to the passive suspension, the improvements are $1.47 \%$, $18.83 \%$ and $10.21 \%$.

It is worth noting that regardless of whether only the coil resistor, only the coil inductor or both the coil resistor and inductor are considered, the RMS of the vehicle body acceleration will decrease, and the RMS of the suspension working space and dynamic tire load will increase.

\section{Conclusion}

In this paper, the impact of the coil factors on the hydraulic electric inerter-based vehicle suspension is investigated. The hydraulic electric inerter (HEI) device was first introduced, and the quarter car model, which is based on the proposed HEI device, was established. The advantages of the proposed vehicle HE-ISD suspension were validated by numerical simulations. Then, by considering the coil resistor and inductor, three scenarios were taken into account. The results showed that the performance of the vehicle HE-ISD suspension will be slightly affected by the coil factors, so that the RMS of the vehicle body acceleration will decrease and that the RMS of the suspension working space and dynamic tire load will, on the contrary, increase. However, the performance indexes are still smaller than those of the passive suspension.

\section{Acknowledgement}

This work was supported by National Natural Science Foundation of China (grant No. 51575238), Natural Science Research Project of Jiangsu Higher Education Institutions (18KJB580001), State Key Laboratory of Automotive Safety and Energy under Project (grant No. KF2001), and China Postdoctoral Science Foundation (grant No. 2019M651723).

\section{References}

1. Amati N., Festini A., Tonoli A., 2011, Design of electromagnetic shock absorbers for automotive suspensions, Vehicle System Dynamics, 49, 12, 1913-1928

2. Chen S.A., Li X., Zhao L.J., Wang Y.X., Kim Y.B., 2015, Development of a control method for an electromagnetic semi-active suspension reclaiming energy with varying charge voltage in steps, International Journal of Automotive Technology, 16, 5, 765-773

3. Chen S.A., Wang J.C., Yao M., Kim Y.B., 2017, Improved optimal sliding mode control for a non-linear vehicle active suspension system, Journal of Sound and Vibration, 395, 1-25

4. Ding R.K., Wang R.C., Meng X.P., Chen L., 2019, A modified energy-saving skyhook for active suspension based on a hybrid electromagnetic actuator, Journal of Vibration and Control, 25, 2, 286-297

5. Gonzalez-Buelga A., Clare L.R., Neild S.A., Jiang J.Z., Inman D.J., 2015, An electromagnetic inerter-based vibration suppression device, Smart Material and Structures, 24, 5, 1-10

6. Huang C., Chen L., Yuan C.C., Jiang H.B., 2013, Non-linear modelling and control of semi-active suspensions with variable damping, Vehicle System Dynamics, 51, 10, 1568-1587

7. Jiang J.Z., Smith M.C., 2011, Regular positive-real functions and five-element network synthesis for electrical and mechanical networks, IEEE Transactions on Automatic Control, 56, 6, 1275-1290

8. LAZAR I., NeILD S.A., WAGG D.J., 2014, Using an inerter-based device for structural vibration suppression, Earthquake Engineering and Structural Dynamics, 43, 8, 1129-1147 
9. Li Y., JiAng J.Z., NeILd S.A., 2016, Inerter-based configurations for main-landing-gear shimmy suppression, Journal of Aircraft, 54, 2, 684-693

10. Li Y., JiAng J.Z., Neild S.A., WAng H.L., 2017, Optimal inerter-based shock-strut configurations for landing-gear touchdown performance, Journal of Aircraft, 54, 5, 1901-1909

11. Liu X.F., Jiang J.Z., Titurus B., Harrison A., 2018, Model identification methodology for fluid-based inerters, Mechanical Systems and Signal Processing, 106, 479-494

12. LiU Y., XU L., Zuo L., 2017, Design, modeling, lab and field tests of a mechanical-motion-rectifier-based energy harvester using a ball-screw mechanism, IEEE/ASME Transactions on Mechatronics, 22, 5, 1933-1943

13. Papageorgiou C., Houghton N.E., Smith M.C., 2009, Experimental testing and analysis of inerter devices, Journal of Dynamic Systems, Measurement, and Control, 131, 1, 101-116

14. Papageorgiou C., Smith M.C., 2005, Laboratory experimental testing of inerters, Proceedings of the 44th IEEE Conference on Decision and Control, and the European Control Conference, 3351-3356

15. Rashid M.M., Rahim N.A., Hussain M.A., Rahman M.A., 2011, Analysis and experimental study of magnetorheological-based damper for semiactive suspension system using fuzzy hybrids, IEEE Transactions on Industry Applications, 47, 2, 1051-1059

16. Shen Y.J., Chen L., Liu Y.L., Zhang X.L., 2016a, Modeling and optimization of vehicle suspension employing a nonlinear fluid inerter, Shock and Vibration, 2016, 1-11

17. Shen Y.J., Chen L., Liu Y.L., Zhang X.L., 2017, Influence of fluid inerter nonlinearities on vehicle suspension performance, Advances in Mechanical Engineering, 9, 11, 1-10

18. Shen Y.J., Chen L., YAng X.F., Shi D.H., YAng J., 2016b, Improved design of dynamic vibration absorber by using the inerter and its application in vehicle suspension, Journal of Sound and Vibration, 361, 148-158

19. Shen Y.J., Liu Y.L., Chen L., Yang X.F., 2019a, Optimal design and experimental research of vehicle suspension based on a hydraulic electric inerter, Mechatronics, 61, 12-19

20. Shen Y.J., Shi D.H., Chen L., Liu Y.L., YAng X.F., 2019b, Modeling and experimental tests of hydraulic electric inerter, Science China Technological Sciences, 62, 12, 2161-2169

21. Shi D.H., Chen L., Wang R.C., Jiang H.B., Shen Y.J., 2014, Design and experiment study of a semi-active energy-regenerative suspension system, Smart Materials and Structures, 24, 1-12

22. Sмiтh M.C., 2002, Synthesis of mechanical networks: the inerter, IEEE Transactions on Automatic Control, 47, 10, 1648-1662

23. Sмith M.C., Wang F.C., 2004, Performance benefits in passive vehicle suspensions employing inerters, Vehicle System Dynamics, 42, 4, 235-257

24. Sun X.Q., Chen L., Wang S.H., Zhang X.L., Yang X.Y., 2016, Performance investigation of vehicle suspension system with nonlinear ball-screw inerter, International Journal of Automotive Technology, 17, 3, 399-408

25. Swift S.J., Smith M.C., Glover A.R., 2013, Design and modelling of a fluid inerter, International Journal of Control, 86, 11, 2035-2051

26. Wang F.C., Chan H., 2011, Vehicle suspension with a mechatronic network strut, Vehicle System Dynamics, 49, 5, 811-830

27. Wang F.C., Hong M.F., Chen C.W., 2010, Building suspension with inerters, Proceedings of the Institution of Mechanical Engineers, Part C: Journal of Mechanical Engineering Science, 224, 8, 1605-1616

28. Wang R.C., Ye Q., Sun Z.Y., Zhou W.Q., Cao Y.C., Chen L., 2017, A study of the hydraulically interconnected inerter-spring-damper suspension system, Mechanics Based Design of Structures and Machines, 45, 4, 415-429 
29. Xue W.P., Li K.Q., Chen Q., 2019, Mixed FTS/H-infinity control of vehicle active suspensions with shock road disturbance, Vehicle System Dynamics, 57, 6, 841-854

30. Yang X.F., Shen Y.J., YAng J., 2015, A hydraulic-electric impedance control device of vehicle suspension system (in Chinese), CN201520074528.3

Manuscript received November 6, 2019; accepted for print December 10, 2019 